\title{
Prevalence of herbal and dietary supplement usage in Thai outpatients with chronic kidney disease: a cross-sectional survey
}

Mayuree Tangkiatkumjai ${ }^{*}$, Helen Boardman ${ }^{2}$, Kearkiat Praditpornsilpa ${ }^{3}$ and Dawn M Walker ${ }^{1}$

\begin{abstract}
Background: There are few studies of the prevalence and patterns of herbal and dietary supplement (HDS) use in patients with chronic kidney disease (CKD), although many researchers and health professionals worldwide have raised concern about the potential effects of HDS on patients with renal insufficiency. A survey was conducted to determine: the prevalence and patterns of HDS use in Thai patients with CKD; the demographic factors related to HDS use; the reasons why Thai patients with CKD use HDS; respondent experiences of benefits and adverse effects from HDS; and the association between conventional medication adherence and HDS use.
\end{abstract}

Methods: This cross-sectional survey recruited patients with CKD attending two teaching hospitals in Thailand. Data were collected via an interview using a semi-structured interview schedule regarding demographics, HDS usage, reasons for HDS use, and respondent experiences of effects from HDS. Conventional medication adherence was measured using the Thai version of 8-Item Morisky Medication Adherence Scale. Descriptive statistics were used to analyse the prevalence and the patterns of HDS use. Chi-square tests and multiple logistic regression were used to determine any associations between HDS use, demographics and conventional medication adherence.

Results: Four hundred and twenty-one eligible patients were recruited. The prevalence of HDS use in the previous 12 months was 45\%. There were no demographic differences between HDS users and non-users, except former drinkers were less likely to use HDS, compared with non-drinkers (OR $0.43,95 \% \mathrm{Cl} 0.25-0.75)$. Those with a medium level of adherence to conventional medication were less likely to use HDS compared with those with a low level of adherence (OR 0.53, 95\% Cl 0.32-0.87). Maintaining well-being was most common purpose for using HDS (36\%). Nearly $18 \%$ used HDS, such as holy mushroom, river spiderwort and boesenbergia, to treat kidney disease. The top three most often reported reasons why respondents used HDS were family and friend's recommendation, followed by expecting to gain benefit from HDS and wanting to try them. Perceived beneficial effects on renal function from HDS were reported by around 10\% of HDS users. Among HDS users, seven patients perceived worsening CKD from HDS, such as river spiderwort, kariyat and wheatgrass. Additionally, $72 \%$ of respondents did not inform their doctor about their HDS use mainly because their doctor did not ask (46\%) or would disapprove of their HDS use (15\%).

Conclusions: Around half of the Thai patients with CKD used HDS. Health professionals should be aware of HDS use amongst such patients and enquire about HDS use as a part of standard practice in order to prevent any detrimental effects on kidney function.

\footnotetext{
* Correspondence: mcxmt3@nottingham.ac.uk

'Division of Primary Care, School of Community Health Sciences, University of Nottingham, Nottingham, UK

Full list of author information is available at the end of the article
} 


\section{Background}

There is widespread use of herbal and dietary supplement (HDS), particularly in Asian countries [1]. The prevalence of HDS use in the general population ranges from $22 \%$ to $77 \%$ across Asian countries [2-7]. Patients with chronic diseases, such as diabetes, cardiovascular diseases and cancer have been reported as being more likely to use HDS [8] and the prevalence of HDS use in these populations ranges from $32 \%$ to $77 \%$ in Thailand, the US and Malaysia [9-13]. There are no differences in the demographic characteristics between HDS users and non-users in patients with chronic illnesses, including CKD regarding age, gender, education and smoking status $[9,11,14]$. This differs from HDS users in the general populations, who are more likely to be elderly, female, and educated to a higher level in both Asian and western countries $[5,15,16]$. Whilst patients in Asian countries reported family and friend's recommendations $[9,13,17]$ as the main reason for using either complementary and alternative medicine (CAM) or herbal medicine, amongst patients with chronic diseases in the US they are used to supplement conventional medicines and because patients want to try HDS [18]. Spanner and Duncan state that prevention is the main reason for using HDS amongst patients with CKD [14]. Although populations with long term conditions have a higher prevalence of HDS use, more than half of patients with chronic illnesses reported not informing either their doctor or health care providers about their HDS use $[9,12,13,17,18]$. In contrast, patients with CKD were more likely to inform their health care providers about their HDS use (55-67\%) [14,19].

The use of CAM, including HDS use has been shown to be related to poor adherence to conventional medication [20,21]. However, Cherniack (2011) found no association between CAM use and medication adherence [22]. There are limited and controversial suggestions as to whether HDS use negatively influences conventional medication adherence [20-23] due to depressive symptoms, costs of conventional medications and dis-satisfaction with the doctor-patient relationship in patients with hypertension [20].

Chronic kidney disease (CKD) is a worldwide health problem leading to a decreased quality of life and increased mortality, and is a condition where the kidneys no longer function as they should due to a decrease in kidney mass, development of glomerular hypertension and intratubular proteinuria. It is classified on a scale of $1-5$ based on a level of glomerular filtration rate, with 5 being the lowest level of function. There is a high prevalence of stage 3-5 CKD in the Thai population (8.9\%) [24], compared to the median worldwide prevalence of CKD (7.2\%) [25]. Stage 3-5 CKD, an estimated glomerular filtration rate (eGFR) of less than $60 \mathrm{ml} / \mathrm{min}$, is associated with a high number of complications [26] so these patients may be more vulnerable to any
HDS adverse effects. Additionally, it has been documented in many recent studies that several HDS induce adverse renal effects ranging from worsening kidney function to renal failure, these include aristolochic acid, fangchi and Lglutamine $[2,4,27-30]$. This has led to concerns about detrimental effects of HDS use in patients with CKD. Despite the concerns of practitioners, only a few surveys in western countries have investigated HDS use in patients with CKD [14,19]. Grabe and Garrison (2004) in the US found 29\% of patients with CKD used HDS, whilst Spanner and Duncan (2005) in Canada reported 45\% used HDS. However, these studies had small populations and did not investigate patient's experiences of positive and negative effects of HDS on kidney function or the association between HDS use and adherence to conventional medication. Given the concerns about the effect of HDS on renal function and the higher prevalence of HDS use in Asian countries, it is important to establish the extent and patterns of use amongst CKD patients in Asian countries so health care providers can be better informed and advise their patients accordingly.

To promote herb product use amongst Thai residents and to provide appropriate dosage regimens and indications for such products, the Thai Food and Drug Administration has issued guidance for their safe and effective use [31]. Seventy-one items of Thai folk herbal products, both herbal combinations and single herbal medicines, are in the Thai National List of Essential Medicines (2011). Senna, roselle, java tea and folk remedies, such as 'Ya Hom' and 'Ka sai' are listed in the Thai National List for alleviating common illnesses but are not recommended for patients with renal insufficiency by the Thai Food and Drug Administration. High dose senna can induce nephritis, whilst roselle and java tea can affect electrolyte imbalance in patients with CKD. Ya Hom and Ka Sai contain camphor, which can accumulate in the body and thus result in renal toxicity [31].

The aims of this survey were to determine: the prevalence and patterns of HDS use in Thai patients with CKD; demographic factors related to HDS use, including the association between conventional medication adherence and HDS use; reasons why Thai CKD patients use HDS; and respondent experiences of benefit and adverse effects from HDS.

\section{Methods}

A cross-sectional survey was conducted from January to June 2012 in kidney clinics in two teaching hospitals, King Chulalongkorn Memorial Hospital in Bangkok representing an urban population and HRH Princess Maha Chakri Sirindhorn Medical Center in Nakhon-Nayok province representing a rural population. Both hospitals are in the central part of Thailand, which has the second highest prevalence of CKD in the country [4]. The study was 
approved by the Institutional Review Board for Research in Human Subjects at Faculty of Medicine, Chulalongkorn University and Srinakharinwirot University, Thailand, and the Medical School Research Ethics Committee of the University of Nottingham, UK.

A nineteen-item semi-structured questionnaire was adapted from previously developed surveys on herbal medicine designed by Kuo et al. [32] with added questions in order to achieve the research outcomes. This questionnaire was piloted to test the understanding of the questions and the validity and test-retest reliability (intraclass correlation coefficient $=0.73$ ) in a CKD population of the Thai version of 8-Item Morisky Medication Adherence Scale (MMAS-8) [33]. With respect to validity, low medication adherence measured by MMAS- 8 had a trend towards worsening CKD; however the total number of respondents was not sufficient to estimate the relationship with a standard error of $5 \%$. The final version of questionnaire consisted of four parts, demographic characteristics, HDS use, experiences of benefits and adverse effects from HDS, and the Thai version of MMAS-8, see Additional file 1. Demographic characteristics included age, gender, current address, education, occupation, smoking status and alcohol consumption. Household income was not included as in the pilot study half of the respondents were unwilling to provide this information. HDS usage included types, medical purposes, dosage forms, doses and duration of HDS use, reasons why respondents use HDS, information sources, how they obtained the HDS and the disclosure of HDS use to their doctor.

The prevalence of HDS usage was defined as regular or occasional use during the previous 12 months. HDS were defined as products containing plant-derived material, either raw or processed ingredients, from one or more plants or containing dietary ingredients, such as vitamins, minerals, amino acids and substances, such as, enzymes, organ tissues, glands and metabolites [34,35]. Additionally, this study focused on HDS use for the treatment of illnesses or health promotion rather than consumption for daily food intake or cosmetic purposes and did not include prescribed dietary supplements.

Inclusion criteria were: adult outpatients with CKD diagnosed by a doctor; an eGFR level of less than $60 \mathrm{ml} /$ min calculated by the Thai Modification of Diet in Renal Disease equation [36]; and that the patients attended a kidney clinic at either setting. Patients who had received either dialysis or a kidney transplant were excluded. All patients who met the inclusion criteria were approached by MT and other trained interviewers in order to determine their willingness to participate in this survey. If they consented, a 19-item semi-structured questionnaire with samples of HDS pictures was administered in faceto-face interviews.
Data analysis consisted of simple frequencies with percentages which were used to determine the prevalence of HDS use and descriptive results. Chi-square tests were performed to determine the factors related to HDS use and any associations between HDS use and conventional medication adherence. Multiple logistic regression analyses were undertaken to determine associations between HDS use and demographic characteristics and conventional medication adherence. Tests were 2-tailed, and a pvalue $<0.05$ was considered statistically significant.

\section{Results}

\section{Demographic characteristics of respondents}

The total number of respondents was 444 of which 23 $(5 \%)$ were excluded. Receiving dialysis $(n=15)$ was the main reason for exclusion. Four patients (1\%) did not give their consent and another four patients were unable to provide information due to illnesses. Respondents had a mean age of 66 years (SD \pm 13$)$ and $54 \%$ were women. The majority of respondents were retired (68\%) and had stage 3 CKD (71\%). Comparing demographics between the population in this survey and the Thai general population found that there were no differences regarding gender, education levels, living in urban or rural areas, smoking and drinking status [37]. However, respondents in the present survey were older than the general CKD population (mean $\pm \mathrm{SD}$ : $56.8 \pm 14.5)[24]$.

The prevalence of HDS use amongst patients with CKD was $45 \%$. Almost all HDS users combined them with their prescribed, conventional medicines (99\%). Demographic characteristics of HDS users and non-users are shown in Table 1. Comparisons between HDS users and non-users found that conventional medication adherence differed across the groups with HDS users more likely to have poor medication adherence $(\chi 2=8.46, p=0.015)$, other comparisons found no differences between the groups.

Further analysis using multiple logistic regression found that former drinkers (Odds ratio (OR) 0.43, 95\% CI 0.250.75 ) and respondents having a medium level of adherence to prescribed, conventional medicines (OR 0.53, 95\% CI 0.32-0.87) were less likely to use HDS than nondrinkers and those reporting poor adherence. No other statistically significant factors associated with HDS use were found, see Table 2.

\section{Herbal and dietary supplement use}

Of the respondents using HDS ( $n=189)$, a total of $64 \%$ reported using herbal medicines and 36\% used dietary supplements, with $14 \%$ using both. The mean number of different HDS used was $1.6(\mathrm{SD} \pm 0.9$ ) products. Oral capsules or tablets were the usual forms of HDS used (51\%) of which $11 \%$ were traditional Thai or Chinese pills called 'Luke Klon', which is a black round pill. Seven percent of the products used were non-processed herbs. 
Table 1 Comparison of characteristics between HDS users and non-users $(n=421)$

\begin{tabular}{|c|c|c|c|}
\hline Characteristics & $\begin{array}{c}\text { HDS user } \\
(n=189)\end{array}$ & $\begin{array}{c}\text { Non user } \\
(n=232)\end{array}$ & $x^{2} p$-value \\
\hline$\overline{\text { Age }}$ & & & 0.334 \\
\hline$\leq 60$ & $62(32.8 \%)$ & $66(28.4 \%)$ & \\
\hline$>60$ & $127(67.2 \%)$ & $166(71.6 \%)$ & \\
\hline Gender & & & 0.708 \\
\hline Male & $89(47.1 \%)$ & $105(45.3 \%)$ & \\
\hline Female & $100(52.9 \%)$ & $127(54.7 \%)$ & \\
\hline Education & & & 0.862 \\
\hline $\begin{array}{l}\text { Less than secondary } \\
\text { school }\end{array}$ & $104(55.3 \%)$ & $130(56.0 \%)$ & \\
\hline Secondary school & $27(14.4 \%)$ & $40(17.2 \%)$ & \\
\hline Vocational degree & $14(7.4 \%)$ & $15(6.5 \%)$ & \\
\hline $\begin{array}{l}\text { Undergraduate } \\
\text { degree }\end{array}$ & $34(18.1 \%)$ & 35 (15.1\%) & \\
\hline $\begin{array}{l}\text { Higher than } \\
\text { undergraduate degree }\end{array}$ & $9(4.8 \%)$ & $12(5.2 \%)$ & \\
\hline Address & & & 0.186 \\
\hline Capital city & $60(31.7 \%)$ & 88 (37.9\%) & \\
\hline Rural areas & $129(68.3 \%)$ & $144(62.1 \%)$ & \\
\hline Smoking status & & & 0.812 \\
\hline Never & $122(64.6 \%)$ & $147(63.4 \%)$ & \\
\hline Former & $59(31.2 \%)$ & $72(31.0 \%)$ & \\
\hline Current & $8(4.2 \%)$ & $13(5.6 \%)$ & \\
\hline Alcoholic consumption & & & 0.080 \\
\hline Never & $119(63.3 \%)$ & $121(52.4 \%)$ & \\
\hline Former & $60(31.9 \%)$ & $96(41.5 \%)$ & \\
\hline Current & $9(4.8 \%)$ & $14(6.1 \%)$ & \\
\hline Stages of CKD & & & 0.936 \\
\hline 3 & $133(70.4 \%)$ & $164(70.7 \%)$ & \\
\hline 4 & 49 (25.9\%) & $58(25.0 \%)$ & \\
\hline 5 & $7(3.7 \%)$ & $10(4.3 \%)$ & \\
\hline Medication adherence** & & & $0.015^{*}$ \\
\hline Low & $61(32.3 \%)$ & 47 (20.2\%) & \\
\hline Medium & $79(41.8 \%)$ & $122(52.6 \%)$ & \\
\hline High & 49 (25.9\%) & $63(27.2 \%)$ & \\
\hline
\end{tabular}

* Statistically significant at $\mathrm{p}<0.05$; ${ }^{* *}$ Medication adherence was measured using the Thai version of 8-Item Morisky Medication Adherence Scale; Low, medium and high adherence was defined as MMAS $<6,6 \leq$ MMAS $<8$, MMAS $=8$, respectively.

Nearly three quarters of the products were used daily (71\%) and half of products had been used for less than a year (52\%).

Purposes of using HDS were for maintaining wellbeing (36\%), followed by the treatment of other chronic diseases (24\%), minor ailments (19\%), and kidney diseases (17\%). Herbs tended to be used for illnesses,
Table 2 Multiple logistic regression analysis of factors related to HDS use in patients with CKD $(n=421)$

\begin{tabular}{|c|c|c|}
\hline Factors & Odds ratio & $\begin{array}{c}\text { 95\% Confidence } \\
\text { interval }\end{array}$ \\
\hline \multicolumn{3}{|l|}{$\overline{\text { Age }}$} \\
\hline$\leq 60$ & 1.00 & \\
\hline$>60$ & 0.84 & $0.52-1.36$ \\
\hline \multicolumn{3}{|l|}{ Gender } \\
\hline Male & 1.00 & \\
\hline Female & 0.77 & $0.47-1.29$ \\
\hline \multicolumn{3}{|l|}{ Education } \\
\hline Less than secondary school & 1.00 & \\
\hline Secondary school & 0.77 & $0.43-1.40$ \\
\hline Vocational degree & 1.11 & $0.48-2.52$ \\
\hline Undergraduate degree & 1.16 & $0.64-2.11$ \\
\hline Higher than undergraduate degree & 0.88 & $0.33-2.36$ \\
\hline \multicolumn{3}{|l|}{ Current address } \\
\hline Capital city & 1.00 & \\
\hline Rural address & 1.38 & $0.90-2.12$ \\
\hline \multicolumn{3}{|l|}{ Smoking status } \\
\hline Never smoked & 1.00 & \\
\hline Former smoker & 1.57 & $0.85-2.89$ \\
\hline Current smoker & 0.90 & $0.33-2.47$ \\
\hline \multicolumn{3}{|l|}{ Alcohol consumption } \\
\hline Never & 1.00 & \\
\hline Former drinker & 0.43 & $0.25-0.75$ \\
\hline Current drinker & 0.52 & $0.20-1.33$ \\
\hline \multicolumn{3}{|l|}{ Stages of CKD } \\
\hline 3 & 1.00 & \\
\hline 4 & 1.02 & $0.64-1.64$ \\
\hline 5 & 0.92 & $0.32-2.63$ \\
\hline \multicolumn{3}{|c|}{ Prescribed, conventional medication adherence } \\
\hline Low & 1.00 & \\
\hline Medium & 0.53 & $0.32-0.87$ \\
\hline High & 0.68 & $0.39-1.20$ \\
\hline
\end{tabular}

including other chronic diseases, kidney diseases, minor ailments and leg oedema (80\%); whereas most dietary supplements were used for well-being (69\%).

Family and friends were an important influencing factor for respondents choosing to use HDS (35\%). They provided not only HDS information (52\%), but also the HDS products $(27 \%)$, see Table 3 . The next most frequently cited reasons for HDS use were that respondents perceived that they would gain benefits from the HDS (22\%) and were willing to try HDS (19\%). Television, radio and internet (23\%) were reported as the second sources of HDS information, followed by health care providers (5\%). 


\section{Table 3 Reasons for HDS use and information sources $(n=189)$}

\begin{tabular}{lcc}
\hline & Frequency & Percentage \\
\hline Reasons ( $\mathrm{n}=317)^{*}$ & 111 & 35.0 \\
Family/friend's recommendation & 71 & 22.4 \\
HDS will work & 61 & 19.2 \\
Willing to try anything that helps & 34 & 10.7 \\
Prefer to use HDS & 21 & 6.6 \\
Health care provider's recommendation & 9 & 2.8 \\
Safer than conventional medicines & 5 & 1.6 \\
Easy access & 2 & 0.7 \\
Recommended by traditional practitioners & & \\
Or HDS sellers & 2 & 0.7 \\
Experienced adverse effects from & & \\
Conventional medicines & 1 & 0.3 \\
Recommended by other patients with CKD & & \\
Information sources ( $\mathrm{n}=222)^{*}$ & 115 & 51.8 \\
Family and friends & 50 & 22.5 \\
TV, radio or internet & 12 & 5.4 \\
Health care providers & 12 & 5.4 \\
Books or newspapers & 8 & 3.6 \\
Traditional practitioners & 7 & 3.1 \\
HDS companies & 7 & 3.1 \\
Leaflets from HDS companies & 7.1 \\
Own knowledge of HDS & 2 & 1.0 \\
Other patients with CKD & & \\
Scientific evidence & & \\
\hline & & \\
Respondents res & & \\
\hline
\end{tabular}

* Respondents reported more than one reason and more than one information source, so these total more than 189.

Most HDS products were bought from pharmacies, herbal or dietary supplement shops (41\%), followed by direct sale HDS companies (30\%) who advertise on satellite television or radio to sell their products. Collecting herbs from their own garden were reported by $9 \%$ of respondents. Importantly, most respondents reported that they did not inform their doctor about HDS use (72\%) and the main reason for this was that their doctor did not ask them (46\%), see Table 4.

Types of HDS use and perception of benefits and adverse effects from HDS

Amongst 304 different HDS used, there were 58 different herbal products and 18 different dietary supplement products used. Of the herbal products, $66 \%$ were a single herbal use and $34 \%$ were a herbal combination. However, 51 HDS products (17\%) were unknown as respondents did not either know or remember their ingredients. Kariyat $(12 \%)$, turmeric $(10 \%)$ and horseradish tree $(8 \%)$ were the three were most used herbs, see Table 5. Senna, folk
Table 4 Disclosure of HDS use to doctors and the reasons for not disclosing $(n=189)$

\begin{tabular}{|c|c|c|}
\hline & Frequency & Percentage \\
\hline \multicolumn{3}{|l|}{ Informed their doctor about their HDS use } \\
\hline Yes & 53 & 28.0 \\
\hline No & 136 & 72.0 \\
\hline \multicolumn{3}{|l|}{ Reasons for not reporting HDS use $(n=144)^{*}$} \\
\hline Health care providers don't ask & 66 & 45.8 \\
\hline $\begin{array}{l}\text { Patients worried that their doctor will } \\
\text { disapprove of HDS use }\end{array}$ & 22 & 15.3 \\
\hline Short-term or occasional use & 19 & 13.2 \\
\hline No need to inform their practitioner & 18 & 12.5 \\
\hline $\begin{array}{l}\text { Didn't see their doctor during the } \\
\text { period of HDS use }\end{array}$ & 8 & 5.5 \\
\hline Just start using HDS and no opportunity & 4 & 2.8 \\
\hline Stopping or planning to stop using HDS & 3 & 2.1 \\
\hline Don't want to tell them & 2 & 1.4 \\
\hline HDS are safe & 1 & 0.7 \\
\hline Doesn't influence their disease (s) & 1 & 0.7 \\
\hline
\end{tabular}

* Respondents reported more than one reason, so these total more than 136.

remedies "Ya Hom" and "Ka Sai", java tea and roselle juice were also reported $(6 \%)$.

Vitamins and minerals were the most often reported dietary supplements used $(16 \%, n=17)$ of which vitamin $C(n=6)$ and calcium supplements $(n=4)$ were most common (Table 6), followed by essence of chicken drink (13\%) and germ oil (12\%).

Regarding perception of benefits from HDS, around three quarters of the HDS used were reported to have benefits (74\%). The reported benefits were alleviation of minor ailments, such as constipation (24\%), musculoskeletal pain (19\%) and flatulence (15\%), followed by enhanced wellbeing $(28 \%)$ and slowing the progression of their CKD (9\%) meaning a decrease in serum creatinine. There were nine different HDS which respondents reported slowing the progression of their CKD: Holy mushrooms $(n=3)$, a herbal combination - Boesenbergia, mint, ginger, galangal, lemongrass, kaffir lime leaves and shallots $(\mathrm{n}=1)$, a herbal combination - Boesenbergia, onion, galangal, lemongrass, kaffir lime leaves, lime leaves and mint $(n=1)$, turmeric $(n=1)$, Spring bitter cucumber $(\mathrm{n}=1)$, a Chinese folk remedy Cordyceps, Angelica sinensis, Chinese Wolfberry, Astragalus (Astragalus membranaceus), Eucommia ulmoides, Codonopsis pilosula and deer antler velvet $(\mathrm{n}=1)$, a herbal combination - Jujube, roselle, boesenbergia and mixed 3 types of mushrooms $(\mathrm{n}=1)$, spirulina $(\mathrm{n}=1)$ and mangosteen peel juice $(\mathrm{n}=1)$.

In contrast, only 10\% reported adverse effects from HDS use of which the progression of CKD defined as an increase in serum creatinine or having proteinuria was the 
Table 5 Herbs used; respondents reported purposes and adverse effects $(n=199)$ *

\begin{tabular}{|c|c|c|c|}
\hline Types of herb used & Frequency (\%) & $\begin{array}{l}\text { Main purpose given } \\
\text { by respondents }\end{array}$ & $\begin{array}{l}\text { Adverse effects } \\
\text { experienced }\end{array}$ \\
\hline Kariyat (Andrographis paniculata) & $23(11.6)$ & $\begin{array}{l}\text { Common cold, fever, } \\
\text { sore throat, diabetes }\end{array}$ & Increased $\mathrm{SCr}$ \\
\hline Turmeric (Curcuma longa) & $19(9.5)$ & $\begin{array}{l}\text { Gastrointestinal symptoms**, } \\
\text { constipation, CKD }\end{array}$ & - \\
\hline Horseradish tree (Moringa oleifera) & $16(8.0)$ & Diabetes, hypertension, constipation & Unable to stop bleeding \\
\hline Mixed botanical extract or fruit drink & $12(6.0)$ & CKD, diabetes, well-being & - \\
\hline Ginseng (Panax spp.) & $7(3.5)$ & Well-being & - \\
\hline Holy mushroom (Garnoderma lucidum) & $5(2.5)$ & CKD & Oedema \\
\hline River spiderwort (Tradescantia fluminensis) & $4(2.0)$ & CKD & Increased SCr, fatigue \\
\hline Babbler's Bill Leaf (Thunbergia laurifolia) & $3(1.5)$ & Detoxification, diabetes & - \\
\hline Senna (Senna alexandrina) & $3(1.5)$ & Constipation & - \\
\hline Ginkgo (Ginkgo biloba) & $3(1.5)$ & Improved brain function & - \\
\hline Boesenbergia (Boesenbergia rotunda) & $3(1.5)$ & CKD & - \\
\hline Garlic & $3(1.5)$ & Dyslipidemia & - \\
\hline Mixed Thai traditional herbs called "Ya Hom" & $3(1.5)$ & Well-being, fainting, dizziness & - \\
\hline Heart-leaved moonseed (Tinospora cripa) & $3(1.5)$ & Diabetes,well-being & - \\
\hline Coix seed (Semen Coicis) & $3(1.5)$ & CKD, well-being, diabetes & - \\
\hline Vap Ca (Houttuynia cordata) & $2(1.0)$ & Kidney stones, CKD & - \\
\hline Aloe (Aloe vera) & $2(1.0)$ & Diuretic effects, well-being & - \\
\hline Blue Pea (Clitoria ternatea) & $2(1.0)$ & CKD & - \\
\hline Mixed 3 or 6 types of mushrooms & $2(1.0)$ & CKD & - \\
\hline Shiitake mushroom (Lentinus edodes) & $2(1.0)$ & CKD, well-being & - \\
\hline Cinnamon (Cinnamomum verum) & $2(1.0)$ & Diabetes & - \\
\hline Mixed Thai traditional herbs called "Ya Khom" & $2(1.0)$ & Fever & - \\
\hline Mixed Thai traditional herbs called "Ka Sai" & $2(1.0)$ & Constipation, well-being & - \\
\hline Jujube (Zizyphus mauritiana) and Roselle (Hibiscus sabdariffa) & $2(1.0)$ & CKD, dyslipidemia & - \\
\hline Spirulina & $2(1.0)$ & Detoxification, diabetes & - \\
\hline Lemongrass & $1(0.5)$ & Dyslipidemia and CKD & - \\
\hline Boesenbergia, sweet basil, honey and lime juice & $1(0.5)$ & CKD & Fainting \\
\hline $\begin{array}{l}\text { Boesenbergia, mint, ginger, galangal, lemongrass, } \\
\text { kaffir lime leaves and shallots }\end{array}$ & $1(0.5)$ & CKD & - \\
\hline Spring bitter cucumber (Momordica cochinchinensis) & $1(0.5)$ & CKD & - \\
\hline Lime & $1(0.5)$ & Kidney stones & - \\
\hline $\begin{array}{l}\text { Chinese folk remedy - Cordyceps, Lovage (Angelica sinensis), deer } \\
\text { antler velvet, cinnamon and Schisandra berry (Schisandra chinensis) }\end{array}$ & $1(0.5)$ & CKD & - \\
\hline $\begin{array}{l}\text { Paragrass roots (Brachiaria mutica) and pomegranate leaves } \\
\text { (Punica granatum) }\end{array}$ & $1(0.5)$ & CKD & - \\
\hline Leaves of Clerodendrum petasites & $1(0.5)$ & CKD & - \\
\hline Java tea & $1(0.5)$ & Diuretic effects & - \\
\hline
\end{tabular}

* Respondents reported more than one type of herb used.

** Flatulance, dyspepsia and peptic ulcers; $\mathrm{SCr}=$ Serum creatinine.

most often reported adverse effect (37\%), followed by gastrointestinal symptoms (16\%) and neurological symptoms (16\%). Three products with reported increased serum creatinine were products where the respondents did not know the ingredients.

\section{Discussion}

The population in the current survey (mean \pm SD: $66 \pm 13$ ) was older than Thai general CKD population (mean \pm SD: $56.8 \pm 14.5$ ) [24]. However, there was no significant difference comparing with literature on the prevalence of 
Table 6 Dietary supplements used; respondents reported purposes and adverse effects $(n=105)$ *

\begin{tabular}{lccc}
\hline Types of dietary supplement used & Frequency (\%) & Purposes given by respondents & Adverse effects experienced \\
\hline Vitamins and minerals & $17(16.2)$ & Well-being & Weight gain \\
Essence of chicken drink & $14(13.3)$ & Well-being & Well-being \\
Germ oil & $13(12.4)$ & Well-being, CKD, diabetes & Inceased blood sugar \\
Rice Bran oil & $9(8.6)$ & Well-being, cardiovascular diseases & - \\
Fish oil & $8(7.6)$ & Well-being & Proteinuria \\
Protein & $7(6.7)$ & Well-being, CKD, diabetes, hypertension & - \\
Chlorophyll & $6(5.7)$ & Well-being & - \\
Swiftlet's nest drink & $5(4.8)$ & Well-being & - \\
Bee pollen & $2(1.9)$ & Well-being & Increased SCr \\
Wheatgrass & $2(1.9)$ & Constipation & - \\
Fibre & $2(1.9)$ & Well-being & Diarrhoea \\
Coconut oil & $1(0.9)$ &
\end{tabular}

* Respondents reported more than one type of dietary supplement used; $\mathrm{SCr}=$ Serum creatinine.

HDS use amongst patients with CKD in Canada (HDS

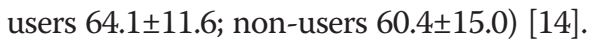

The prevalence of HDS use amongst Thai CKD patients was $45 \%$. There were no differences in demographic characteristics between HDS users and non-users in relation to age, gender, smoking status or education. Although this prevalence cannot be directly compared with previous surveys of HDS use in Thailand due to the different definition of HDS use, this prevalence is similar to a survey of HDS use in Thai patients with chronic diseases (45\%) [10]. We found the prevalence of HDS use in patients with CKD was greater than the prevalence of herbal use in Thai general population (33\%) [4]. The prevalence of the current study is consistent with Spanner and Duncan's survey (2005) in Canada [14], although their study was using a different population, and they used slightly different definitions of HDS use - defined as current daily intake by Spanner and Duncan.

The current study found a significant association between HDS use and poor adherence to conventional medication. However, there was no relationship between HDS use and a high level of adherence to conventional medication. Reasons for these associations are unknown. Likewise, Krousel-Wood et al. (2010) in the US and Gohar et al. (2008) in the UK found a significant association between the use of CAM and a low level of adherence to conventional medicines amongst patients with hypertension, the association was stronger in AfricanAmericans and women [20,21]. There is no clear pattern of this association and the reason for the association has not been investigated, so further studies are needed before firm conclusions can be made.

Non-drinkers were more likely to use HDS than former drinkers in the current survey. However, there is no literature describing the association between HDS use and drinking in patients with chronic diseases. Our results contrast with US national surveys of CAM users amongst young adults in 2000 where they found former drinkers were more likely to use CAM [38]. This difference could be due to the differing populations especially in relation to age. Further studies are required to examine this association in patients with other chronic diseases.

Treatment of chronic kidney diseases was not the main purpose in using HDS. Almost all patients combined HDS with conventional medicines rather using it as a substitute. There is some consistency with surveys of either CAM or herbal use amongst patients with chronic illnesses in Asian and western countries $[9,12,17,18]$. All HDS products reported as being used for CKD, except Astragalus membranaceus, have no scientific evidence to demonstrate their efficacy from clinical trials. Proteinuria, which indicates worsening kidney function, was reported as an adverse effect of using protein supplements - high protein intake is related to a decrease in renal function [39]. River spiderwort, kariyat and wheatgrass were reported by respondents to increase serum creatinine. However, there is no evidence in the literature to support this and therefore research is needed to determine whether or not such HDS would be harmful or beneficial to patients with CKD.

The Thai National List of Essential Medicines (2011) states that for patients with CKD senna, java tea, roselle, Ya Hom and Ka sai are not recommended [31]. However, we found that some respondents used these products $(6 \%)$. Given the low number of respondents who reported their HDS use to their doctor, health care providers need to ask patients about such HDS use and explain why it could worsen their condition.

Family and friends influence patient's decision-making regarding HDS use amongst Asian populations as supported by this study and other studies of either CAM or herbal use in patients with chronic illnesses in Thailand and Malaysia $[9,12,13,17]$. Wanting to try HDS was an often reported 
reason for using HDS, which was also been reported in other surveys of CAM use amongst patients with chronic illnesses in both Asian and western countries [12,18].

Several surveys in Thailand, Malaysia and the US have reported that most patients with chronic diseases, other than CKD, did not disclose their HDS use to their conventional health care providers $[9,12,17,18,40]$. In contrast, patients with CKD in Canada and the US were more likely to inform their doctor about their HDS use (67\% and 55\%, respectively) than patients with other chronic diseases $(33 \%)[14,19]$. However, this contrasts with the current study and should be highlighted that most patients in this study did not inform their doctor about their HDS use (72\%). It would seem that an Asian population is less likely to disclose their HDS use to their conventional health professionals, compared with western populations [40]. Most often reported reasons of non-disclosure were that their doctor did not enquire, they may disapprove of their HDS use or they did not need to know about their HDS use, which is consistent with Robinson and McGrail's systematic review [41].

The findings suggest that conventional health care providers should be aware of the prevalence of HDS use in patients with CKD. They should always ask about their patient's use of HDS, monitor the impact of HDS on CKD, and be prepared to discuss information about how to safely use HDS products with the patient and their caregivers.

\section{Conclusions}

Around half of Thai patients with CKD used HDS; however most of them did not disclose this use to their conventional health care providers. HDS use was significantly associated with a low level of adherence to conventional medicine. Some products were reported to be used to treat their CKD and were perceived to have beneficial effects on kidney function - despite any robust clinical evidence of efficacy. Moreover, some patients perceived renal adverse effects from HDS, which have never been reported in the literature. These findings should be addressed by conventional health care providers in order to prevent detrimental effects of HDS on patients with CKD. Health care providers should enquire about HDS use in patients with CKD as a part of standard practice. Sellers of HDS should ensure appropriate information about their products safety is available to purchasers. Further studies are required to investigate the efficacy and safety of HDS used by patients with CKD.

\section{Additional file}

Additional file 1: Questionnaire of HDS use. The questionnaire adapted from Kuo et al. and consisted of demographics, patterns of HDS use, experiences of benefits and adverse effects from HDS, and the 8-item Morisky medication adherence questionnaire.
Competing interests

The authors declare that they have no competing interests.

\section{Authors' contributions}

MT conceived the study, performed the statistical analysis, coordination of the study and drafted the manuscript. KP advised on the feasibility of the study and participated in coordination of the study. MT, DMW and HB designed the study, the questionnaire and data analyses. All authors reviewed the manuscript and have read and approved the final manuscript.

\section{Acknowledgements}

This study was funded by the Royal Thai Government. Permission to use the 8-Item MMAS was obtained from Dr. Donald E. Morisky. We would like to thank the patient who gave their time to be interviewed by MT, Panjit Chaiyasanit and Piya Kaewkrachang. We would like to thank Dr. Phantipa Sakthong for the permission to use the Thai version of this questionnaire, doctors and nurses at an outpatient kidney clinic in Chulalongkorn hospital and pharmacists at outpatient department of pharmacy in HRH Princess Maha Chakri Sirindhorn Medical Center for access to their patients.

\section{Author details}

'Division of Primary Care, School of Community Health Sciences, University of Nottingham, Nottingham, UK. ${ }^{2}$ Division of Social Research in Medicines and Health, School of Pharmacy, University of Nottingham, Nottingham, UK. ${ }^{3}$ Division of Nephrology, Department of Medicine, Faculty of Medicine, Chulalongkorn University, Bangkok, Thailand.

Received: 4 January 2013 Accepted: 20 June 2013

Published: 1 July 2013

\section{References}

1. Traditional Medicine. http://www.who.int/mediacentre/factsheets/fs134/en/.

2. Guh JY, Chen HC, Tsai JF, Chuang LY: Herbal therapy is associated with the risk of CKD in adults not using analgesics in Taiwan. Am J Kidney Dis 2007, 49(5):626-633.

3. Hori S, Mihaylov I, Vasconcelos JC, McCoubrie M: Pattern of complementary and alternative medicine use amongst outpatients in Tokyo, Japan. BMC Complement Altern Med 2008, 8:14.

4. Ingsathit A, Thakkinstian A, Chaiprasert A, Sangthawan P, Gojaseni P, Kiattisunthorn K, Ongaiyooth L, Vanavanan S, Sirivongs D, Thirakhupt $P$, et al: Prevalence and risk factors of chronic kidney disease in the Thai adult population: Thai SEEK study. Nephrol Dial Transplant 2010, 25(5):1567-1575.

5. Aziz Z, Tey NP: Herbal medicines: prevalence and predictors of use among Malaysian adults. Complement Ther Med 2009, 17(1):44-50.

6. Ock SM, Choi JY, Cha YS, Lee J, Chun MS, Huh CH, Lee SY, Lee SJ: The use of complementary and alternative medicine in a general population in South Korea: results from a National Survey in 2006. J Korean Med Sci 2009, 24(1):1-6.

7. Sydara K, Gneunphonsavath S, Wahlstrom R, Freudenthal S, Houamboun K, Tomson G, Falkenberg T: Use of traditional medicine in Lao PDR. Complement Ther Med 2005, 13(3):199-205.

8. Saydah SH, Eberhardt MS: Use of complementary and alternative medicine among adults with chronic diseases: United States 2002. J Altern Complement Med 2006, 12(8):805-812

9. Moolasarn S, Sripa S, Kuessirikiet V, Sutawee K, Huasary J, Chaisila C, Chechom N, Sankan S: Usage of and cost of complementary/alternative medicine in diabetic patients. J Med Assoc Thai 2005, 88(11):1630-1637.

10. Jiaranaikajorn T, Panthawangkul J, Thamlikitkul V: Use of alternative medicines among medical patients at Siriraj Hospital. Siriraj Med J 2002, 54(10):603-610.

11. Stys $T$, Stys A, Kelly P, Lawson W: Trends in use of herbal and nutritional supplements in cardiovascular patients. Clin Cardiol 2004, 27(2):87-90.

12. Hasan SS, Ahmed SI, Bukhari NI, Loon WCW: Use of complementary and alternative medicine among patients with chronic diseases at outpatient clinics. Complement Ther Clin Pract 2009, 15(3):152-157.

13. Moolasarn S, Sripa S, Kuesirikiet V, Sutawee K, Huasary J, Chaisila C, Chuechom N, Sankarn S: Usage of alternative medicine in cancer patients. Siriraj Med J 2003, 55(6):307-323.

14. Spanner ED, Duncan AM: Prevalence of dietary supplement use in adults with chronic renal insufficiency. J Ren Nutr 2005, 15(2):204-210. 
15. Marques-Vidal P, Pecoud A, Hayoz D, Paccaud F, Mooser V, Waeber G, Vollenweider P: Prevalence and characteristics of vitamin or dietary supplement Users in Lausanne, Switzerland: the CoLaus Study. Eur J Clin Nutr 2009, 63(2):273-281

16. Al-Windi A, Elmfeldt D, Svardsudd K: The relationship between age, gender, well-being and symptoms, and the use of pharmaceuticals, herbal medicines and self-care products in a Swedish Municipality. Eur J Clin Pharmacol 2000, 56(4):311-317.

17. Saw JT, Bahari MB, Ang HH, Lim YH: Herbal use amongst multiethnic medical patients in Penang Hospital: pattern and perceptions. Med J Malaysia 2006, 61(4):422-432

18. Yeh GY, Davis RB, Phillips RS: Use of complementary therapies in patients with cardiovascular disease. Am J Cardiol 2006, 98(5):673-680.

19. Grabe DW, Garrison GD: Comparison of natural product use between primary care and nephrology patients. Ann Pharmacother 2004, 38(7):1169-1172.

20. Krousel-Wood MA, Muntner P, Joyce CJ, Islam T, Stanley E, Holt EW, Morisky $D E, H e J$, Webber LS: Adverse effects of complementary and alternative medicine on antihypertensive medication adherence: findings from the cohort study of medication adherence among older adults. J Am Geriatr Soc 2010, 58(1):54-61.

21. Gohar F, Greenfield SM, Beevers DG, Lip GYH, Jolly K: Self-care and adherence to medication: a survey in the Hypertension Outpatient Clinic. BMC Complement Altern Med 2008, 8(8):4-12.

22. Cherniack EP: Complementary medicine use is not associated with non-adherence to conventional medication in the elderly: a retrospective study. Complement Ther Clin Pract 2011, 17(4):206-208.

23. Bailey GR, Barner JC, Weems JK, Leckbee G, Solis R, Montemayor D, Pope ND: Assessing barriers to medication adherence in underserved patients with diabetes in Texas. Diabetes Educ 2012, 38(2):271-279.

24. Ong-Ajyooth L, Vareesangthip K, Khonputsa P, Aekplakorn W: Prevalence of chronic kidney disease in Thai adults: a National Health Survey. BMC Nephrol 2009, 10:35.

25. Zhang QL, Rothenbacher D: Prevalence of chronic kidney disease in population-based studies: systematic review. BMC Publ Health 2008, 11(8):117-130.

26. National Kidney Foundation: Association of level of GFR with complications in adults. Am J Kidney Dis 2002, 39(2 Suppl 1):S111-S169.

27. Lai MN, Lai JN, Chen PC, Hsieh SC, Hu FC, Wang JD: Risks of kidney failure associated with consumption of herbal products containing Mu Tong or Fangchi: a population-based case-control study. Am J Kidney Dis 2010, 55(3):507-518.

28. Tsai SY, Tseng HF, Tan HF, Chien YS, Chang CC: End-stage renal disease in Taiwan: a case-control study. J Epidemiol 2009, 19(4):169-176.

29. Galera SC, Fechine FV, Teixeira MJ, Coelho ZCB, de Vasconcelos RC, de Vasconcelos PRL: The safety of oral use of L-Glutamine in middle-aged and elderly individuals. Nutrition 2010, 26(4):375-381.

30. Debelle FD, Vanherweghem $J$, Nortier JL: Aristolochic acid nephropathy: a worldwide problem. Kidney Int 2008, 74(2):158-169.

31. National Drug Committee: National List of Herbal Medicine Products. 1st edition. Bangkok: Ministry of Public Health Thailand; 2011

32. Kuo GM, Hawley ST, Todd WL, Balkrishnan R, Volk RJ: Factors associated with herbal use among urban multiethnic primary care patients: a crosssectional survey. BMC Complement Altern Med 2004, 4:18.

33. Sakthong P, Chabunthom R, Charoenvisuthiwongs R: Psychometric properties of the Thai version of the 8-Item Morisky medication adherence scale in patients with type 2 diabetes. Ann Pharmacother 2009, 43(5):950-957.

34. General Guidelines for Methodologies on Research and Evaluation of Traditional Medicine. http://whqlibdoc.who.int/hq/2000/ WHO_EDM_TRM_2000.1.pdf.

35. Overview of Dietary Supplements. http://www.fda.gov

36. Praditpornsilpa K, Townamchai N, Chawatanarat T, Tiranathanagul K, Katawatin P, Susantitaphong P, Trakarnvanich T, Kanjanabuch T, Avihingsanon $Y$, Tungsanga $K$, et al: The need for robust validation for MDRD-based glomerular filtration rate estimation in various CKD populations. Nephrol Dial Transplant 2011, 26(9):2780-2785.

37. National Statistical Office. http://web.nso.go.th/.

38. Gardiner P, Kemper KJ, Legedza A, Phillips RS: Factors associated with herb and dietary supplement use by young adults in the United States. BMC Complement Altern Med 2007, 7:39.
39. Knight EL, Stampfer MJ, Hankinson SE, Spiegelman D, Curhan GC: The impact of protein intake on renal function decline in women with normal renal function or mild renal insufficiency. Ann Intern Med 2003, 138(6):460-467.

40. Mehta DH, Gardiner PM, Phillips RS, McCarthy EP: Herbal and dietary supplement disclosure to health care providers by individuals with chronic conditions. J Altern Complement Med 2008, 14(10):1263-1269.

41. Robinson A, McGrail MR: Disclosure of CAM use to medical practitioners: a review of qualitative and quantitative studies. Complement Ther Med 2004, 12(2-3):90-98.

doi:10.1186/1472-6882-13-153

Cite this article as: Tangkiatkumjai et al:: Prevalence of herbal and dietary supplement usage in Thai outpatients with chronic kidney disease: a cross-sectional survey. BMC Complementary and Alternative Medicine 2013 13:153.

\section{Submit your next manuscript to BioMed Central and take full advantage of:}

- Convenient online submission

- Thorough peer review

- No space constraints or color figure charges

- Immediate publication on acceptance

- Inclusion in PubMed, CAS, Scopus and Google Scholar

- Research which is freely available for redistribution

Submit your manuscript at www.biomedcentral.com/submit
C) Biomed Central 